\title{
Organophosphate Esters in Sediment of the Great Lakes
}

Dandan Cao, ${ }^{\dagger}$ Jiehong Guo, ${ }^{\ddagger}$ Yawei Wang, ${ }^{*}, \dagger, \# \odot$ Zhuona Li, ${ }^{\ddagger}$ Kang Liang, ${ }^{\dagger}$ Margaret B. Corcoran, ${ }^{\prime}, I_{\odot}$ Soheil Hosseini, ${ }^{\S}$ Solidea M. C. Bonina, ${ }^{\S}{ }^{\varnothing}$ Karl J. Rockne, ${ }^{\S}$ Neil C. Sturchio, ${ }^{\|, \bigcirc}$ John P. Giesy, ${ }^{\perp}$ Jingfu Liu, ${ }^{\dagger}$ An $\mathrm{Li}^{*},+{ }^{+}$and Guibin Jiang ${ }^{\dagger}$

${ }^{\dagger}$ State Key Laboratory of Environmental Chemistry and Ecotoxicology, Research Center for Eco-Environmental Sciences, Chinese Academy of Sciences, Beijing 100085, China

${ }^{\ddagger}$ School of Public Health, University of Illinois at Chicago, Chicago, Illinois 60612, United States

${ }^{\S}$ Department of Civil and Materials Engineering, University of Illinois at Chicago, Chicago, Illinois 60607, United States

"Department of Earth and Environmental Sciences, University of Illinois at Chicago, Chicago, Illinois 60607, United States

${ }^{\perp}$ Department of Veterinary Biomedical Sciences and Toxicology Centre, University of Saskatchewan, Saskatoon Saskatchewan S7N 5B3, Canada

${ }^{\#}$ University of Chinese Academy of Sciences, Beijing 100049, China

Supporting Information

ABSTRACT: This is the first study on organophosphate ester (OPEs) flame retardants and plasticizers in the sediment of the Great Lakes. Concentrations of 14 OPEs were measured in three sediment cores and 88 Ponar surface grabs collected from Lakes Ontario, Michigan, and Superior of North America. The sum of these OPEs $\left(\Sigma_{14} \mathrm{OPEs}\right)$ in Ponar grabs averaged 2.2, 4.7, and $16.6 \mathrm{ng} \mathrm{g}^{-1} \mathrm{dw}$ in Lakes Superior, Michigan, and Ontario, respectively. Multiple linear regression analyses demonstrated statistically significant associations between logarithm concentrations of $\Sigma_{14}$ OPEs as well as selected congeners in surface grab samples and sediment organic carbon content as well as a newly developed urban distance factor. Temporal trends observed in dated sediment cores from Lake Michigan demonstrated that the recent increase in depositional flux to sediment is dominated by chlorinated OPEs, particularly tris (2-

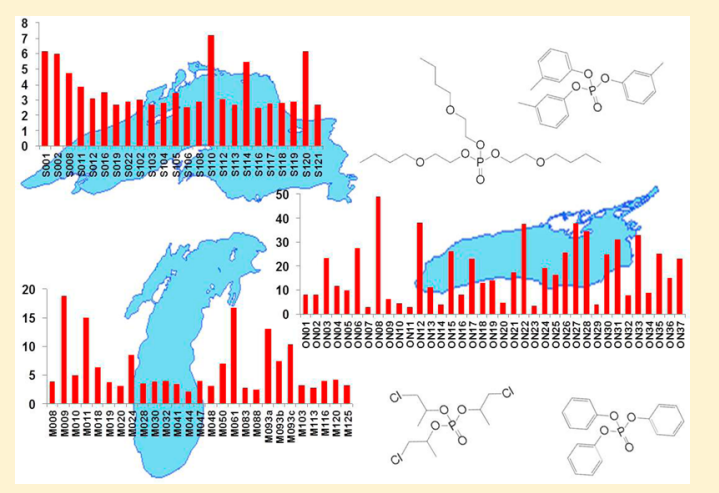
chloroisopropyl) phosphate (TCPP), which has a doubling time of about 20 years. Downward diffusion within sediment may have caused vertical fractionation of OPEs over time. Two relatively hydrophilic OPEs including TCPP had much higher concentrations in sediment than estimated based on equilibria between water and sediment organic carbon. Approximately a quarter (17 tonnes) of the estimated total OPE burden (63 tonnes) in Lake Michigan resides in sediment, which may act as a secondary source releasing OPEs to the water column for years to come.

\section{INTRODUCTION}

Phosphorus is one of the most effective elements for retarding fire. ${ }^{1}$ Organophosphate esters (OPEs) are widely used as flame retardants in plastics, textiles, electronic equipment, furniture, and building materials. ${ }^{2,3}$ Nonchlorinated alkyl phosphates have also been used as plasticizers, hydraulic fluids, lacquer, antifoam agents, glues and extractants for some metals. ${ }^{3}$ Use of OPEs began in the early $20^{\text {th }}$ century, then increased rapidly during the 1940s and continued for later decades. ${ }^{1}$ With the phasing out of polybrominated diphenyl ethers (PBDEs) during the 2000 s, production and use of OPEs as alternative flame retardants have increased significantly in recent years. ${ }^{4,5}$

Similar to other additive flame retardants, OPEs inevitably enter the environment during their production, use and disposal. It was estimated that approximately $80 \%$ of the annual consumption of OPE hydraulic fluids escaped to the environment through leakage from hydraulic systems in the 1960 s. $^{1}$ OPEs have been detected in various environmental compartments, including indoor air and dust, the atmosphere, wastewater and sludge, surface and drinking water, sediment, and biological samples including human blood, milk, and placenta. ${ }^{3,6-8}$ In the United States, there are at least four manufacturers of OPE flame retardants, ${ }^{9}$ although locations of their production facilities are not clear.

In the Great Lakes region, the concentration of OPEs in air was found to be $\sim 100$ - to $\sim 1200$-fold greater than those of brominated flame retardants. ${ }^{10,11}$ Similarly, concentrations of OPEs in water collected from Lakes Erie, Michigan, and Huron were greater than concentrations of brominated flame retardants. ${ }^{12}$ OPEs were also found in fish, herring gulls, and their eggs in the Great Lakes region. ${ }^{13-16}$ Sediments, which can

Received: October 30, 2016

Revised: January 13, 2017

Accepted: January 13, 2017

Published: January 13, 2017 


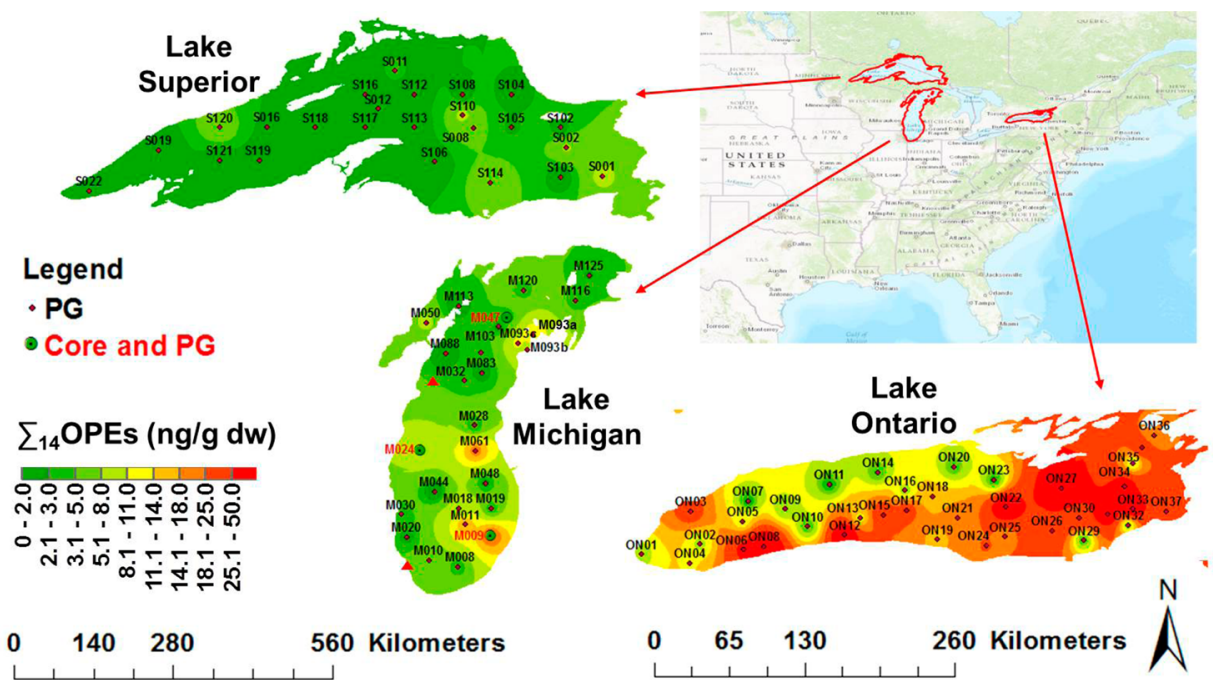

Figure 1. Sampling locations and spatial distribution of $\Sigma_{14}$ OPEs in Ponar grab sediments. The red triangles in Lake Michigan are the bulk water sampling locations from ref 12 . The inverse distance weight (IDW) interpretation in the geostatistical analysis tool of ArcGIS 10.3 (Redlands, CA) was used to illustrate the spatial distribution of $\Sigma_{14}$ OPEs based on measured concentrations in Ponar grab samples.

serve as a sink or potential source of organic pollutants, have been found to be contaminated with OPEs in locations around the world. ${ }^{17-20}$ However, to our knowledge, there were no published reports on OPEs in the sediments of the Great Lakes prior to this study. This represents a major gap in our knowledge of the environmental fate of OPEs in the largest freshwater system in the world.

To date, relatively hydrophobic chemical pollutant groups have been investigated extensively in environmental monitoring efforts, especially those using sediment of natural waters. In comparison, the behavior of persistent organic pollutants with polar functional groups is less understood. Molecules of OPEs possess both polar and nonpolar moieties, and thus are considered amphiphilic. The octanol-water partition coefficient $\left(K_{\mathrm{ow}}\right)$ spans 10 orders of magnitude among the $14 \mathrm{OPE}$ flame retardants and plasticizers listed in the Supporting Information, SI, Table S1. Once in sediment, all of these OPEs are considered persistent with estimated half-lives ranging from months to $>4$ years. $^{21}$

In this work, we report measured concentrations of the 14 OPE flame retardants and plasticizers in sediment samples collected from Lakes Ontario, Michigan, and Superior. The acquired data set enabled an examination of the spatial distribution pattern and temporal trend as well as the influencing factors. The distribution between sediment particulate matter and pore water in the sediment was assessed, based on equilibrium partitioning theory; and the dependence of such phase distributions on the physicochemical property of the analytes was examined.

\section{MATERIALS AND METHODS}

Collection and Characterization of Sediments. Sediments were collected from Lakes Michigan, Superior, and Ontario during 2010 to 2013 onboard the USEPA Research Vessel R/V Lake Guardian. Sampling locations are shown in Figure 1, and site information is provided in Table S2. A total of 88 Ponar grab samples were collected. Sediment cores were collected at three sites in southern (M009), central (M024), and northern (M047) Lake Michigan. Detailed sampling methods are provided in the SI.
Water and solid contents, porosity, wet and dry bulk density, particle density, and sediment organic carbon (OC) were measured by use of standard methods described elsewhere. ${ }^{22}$ Segments of cores were dated by use of profiles of ${ }^{210} \mathrm{~Pb},{ }^{241} \mathrm{Am}$, ${ }^{226} \mathrm{Ra}$, and ${ }^{137} \mathrm{Cs} .{ }^{23}$ Activities of these isotopes were quantified by use of gamma spectroscopy using well-type HPGe detectors. Mass sedimentation rate and focusing factor were derived from activities of ${ }^{210} \mathrm{~Pb}$ as detailed previously. ${ }^{24}$

Identification and Quantification of OPEs. Concentrations were measured for 14 OPEs, including trimethyl phosphate (TMP), triethyl phosphate (TEP), tri- $n$-propyl phosphate (TPrP), tri-iso-butyl phosphate (TiBP), tri- $n$-butyl phosphate (TnBP), tris(2-butoxyethyl) phosphate (TBEP), tris(2-ethylhexyl) phosphate (TEHP), triphenyl phosphate (TPhP), cresyl diphenyl phosphate (CDPP), tri-m-cresyl phosphate (TCrP), 2-ethylhexyl diphenyl phosphate (EHDPP), tris(2-chloroethyl) phosphate (TCEP), tris(2chloroisopropyl) phosphate (TCPP), and tris(1,3-dichloro-2propyl) phosphate (TDCP). Chemical structures and basic information on each of the 14 OPEs are summarized in Table S1.

Laboratory procedures included extraction by ultrasonication, cleanup using solid phase extraction cartridges, and analysis by liquid chromatography-tandem mass spectrometry (LC-MS/MS). Details of these methods are described in SI, and instrument operational parameters are summarized in Table S3. Typical extracted ion chromatograms of a sediment extract and an OPE standard mixture are given in Figure S1.

Quality Control. A matrix blank was a sediment sample from about $50 \mathrm{~cm}$ depth of a core collected in 2011 from the Yellow Sea of China. Fourteen OPEs of $20 \mathrm{ng}$ each were spiked into $1.0 \mathrm{~g}$ of the matrix blank with triplicates. The recoveries of 12 OPEs ranged from $78 \%$ to $108 \%$ (Table S3). The recoveries of EHDPP and TEHP were $47 \%$ and $27 \%$, respectively. The relative standard deviations (RSD) of measured OPE concentrations in the matrix spike ranged from 3\%-13\% except for TEHP, which had an RSD of $38 \%$. Results reported in this paper were not adjusted by the spiking recoveries.

Three field blanks $\left(\mathrm{Na}_{2} \mathrm{SO}_{4}\right.$, prepurified by baking at $500{ }^{\circ} \mathrm{C}$ overnight) from Lakes Superior, Michigan, and Ontario, 


\section{Concentration (ng g $\mathbf{g}^{-1} \mathrm{dw}$ )}
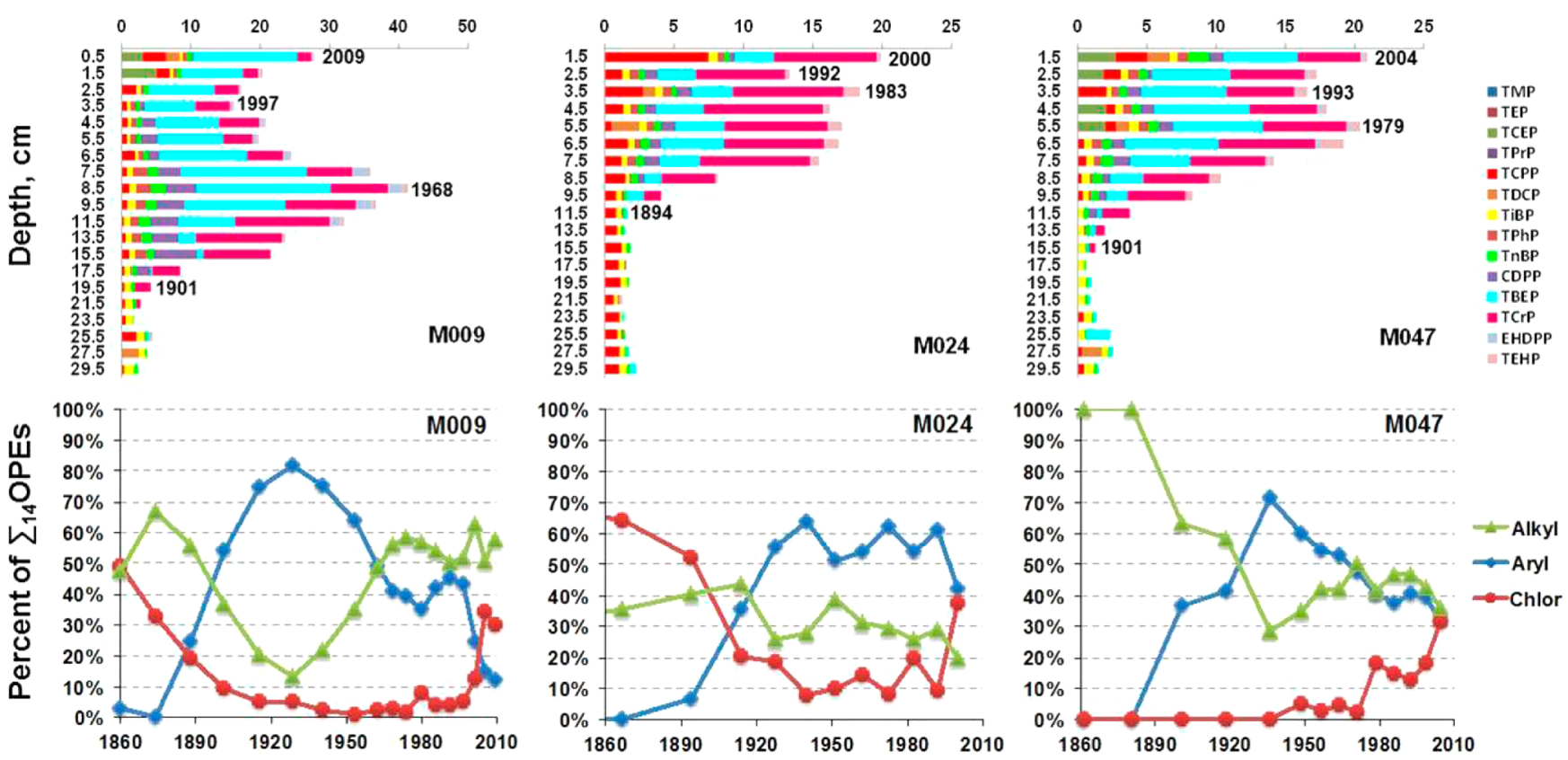

Figure 2. Concentrations of $\Sigma_{14} \mathrm{OPEs}$ against depth in sediment cores from Lake Michigan (upper), and the variations with time in percentages of alkyl- (sum of TMP, TEP, TPrP, TiBP, TnBP, TBEP, and TEHP), aryl- (sum of TPhP, CDPP, TCrP, and EHDPP), and chlorinated (sum of TCEP, TCPP, and TDCP) OPEs (lower).

respectively, were processed in the same manner as collected sediment samples. TCPP, TiBP, TnBP, and TBEP were detected in the field blanks in the concentration range of N.Q. $-0.44 \mathrm{ng} \mathrm{g}^{-1} \mathrm{dw}$. On average, $\Sigma_{14}$ OPEs in the field blank comprised $1 \%, 10 \%$, and $23 \%$ of the concentration in Ponar grab sediment samples from Lakes Ontario, Michigan, and Superior, respectively. One procedural blank (consisting of only extracting solvent) was analyzed with every batch of samples, and TCPP, TiBP, TPhP, and TnBP were commonly detected at lower levels $(<15 \%)$ than those in the samples. The reported concentrations of OPEs in all the sediment samples were after subtractions of the levels measured in the procedural and field blanks.

Data Analyses. In data analysis, N.D. (not detected) was defined as $<$ three times of the signal-to-noise ratio $(S / N<3)$. N.Q. (not quantified) was defined as $S / N>3$ but $<10$. In calculation of the detection rate, samples with N.Q. were included. Both N.Q. and N.D. were replaced by half of the method quantification limits (MQL) in statistical data analysis. MQL of OPEs ranged from 0.04 to $1.4 \mathrm{ng} \mathrm{g}^{-1} \mathrm{dw}$ (Table S3).

Statistical analyses were conducted using SPSS version 18.0 (SPSS Inc.) and Microsoft Excel (2010) with StatPlus (version 5 for Mac OS). Chemical inventories at all sites were estimated with the use of concentration data obtained from both Ponar grab and core samples. Net deposition flux was estimated for each core segment and used to illustrate the time trend. The averages of inventories and fluxes were multiplied by the water surface area of the lakes to estimate the lake-wide total mass load and annual mass loading rate, respectively. Details and equations are provided in the SI.

\section{RESULTS}

Concentrations of $\Sigma_{14} \mathrm{OPEs}$ in Ponar grab samples ranged from 0.44 to $47.82 \mathrm{ng} \mathrm{g}^{-1} \mathrm{dw}$ in the three lakes, and are illustrated in Figure 1. Relative abundance of individual OPEs in Ponar grab samples are illustrated in Figure S2, with site- and congenerspecific data given in Tables S4 and S5, respectively. Concentrations of OPEs in the cores from Lake Michigan are plotted against sediment depth in Figure 2 (upper panels), and are summarized in Table S6. In contrast to the findings in air and water, ${ }^{6,10,12}$ concentrations and accumulations of OPEs in sediments were less than those of polybrominated diphenyl ethers (PBDEs including decabromodiphenyl ether) and polychlorinated biphenyls (PCBs) previously reported for sediments in the Great Lakes. ${ }^{25-27}$ The generally smaller organic carbon-water partition coefficient $\left(K_{\mathrm{oc}}\right)$ of OPEs ${ }^{3}$ (Table S1) compared to those of PBDEs ${ }^{28}$ and $\mathrm{PCBs}{ }^{29}$ indicate less potential for partitioning of OPEs from water to sediment. However, $\Sigma_{14}$ OPEs were higher than the sum of PBDEs with 1 to 7 bromines. $^{25-27}$ Concentrations of $\Sigma_{14}$ OPEs in surface grabs in these three lakes are similar to those from Tai Lake (Ch: Taihu) in China ${ }^{17}$ and Danube river in Austria, ${ }^{18}$ but much lower than those reported in sediments from the Chicago Sanitary and Ship Canal, ${ }^{20}$ rivers in Spain, ${ }^{19}$ a sea-based solid waste disposal site in Japan, ${ }^{30}$ and the Elbe River and its major tributaries in Germany.

Concentrations of $\Sigma_{14}$ OPEs were significantly different among the lakes $(p<0.02)$, with decreasing rank order Lake Ontario > Lake Michigan > Lake Superior (Figure 1, Tables S4 and S5). This rank order is similar to those previously reported for PBDEs, ${ }^{25-27,32} \mathrm{PCBs}^{25-27}$ and other emerging flame retardants. $^{3,34}$ In Lake Superior, concentrations of $\Sigma_{14} \mathrm{OPEs}$ were greater at southeastern sites (S001, S002, and S110) than at other sites (Table S4). Proximity of these sites to the cities of Sault Ste Marie and Marquette, MI, suggests inputs from local sources. In herring gull eggs collected in Agawa Rocks which is near sites S001 and S002, OPE concentrations appear to have greatly increased from 2004 to $2010 .^{16}$ In Lake Michigan, higher concentrations $\left(\Sigma_{14} \mathrm{OPEs}>10 \mathrm{ng} \mathrm{g}^{-1} \mathrm{dw}\right)$ and inventories $\left(>60 \mathrm{ng} \mathrm{cm} \mathrm{cm}^{-2}\right.$ ) were found in the southeast 
Table 1. Estimated Total Loads ( \pm standard error) of OPEs in the Sediments of the Great Lakes $(\mathrm{kg})^{a, b, c}$

$\begin{array}{lcccc} & \text { Lake Superior } & \text { Lake Michigan } & \text { Lake Ontario } & \text { all } 3 \text { Lakes } \\ \text { TMP } & \text { n.a. } & \text { n.a. } & \text { n.a. } & \text { n.a. } \\ \text { TEP } & 800 \pm 190 & \text { n.a. } & \text { n.a. } & 800 \pm 190 \\ \text { TCEP } & 905 \pm 665 & \text { n.a. } & \text { n.a. } & 906 \pm 665 \\ \text { TPrP } & \text { n.a. } & \text { n.a. } & 886 \pm 147 & \text { n.a. } \\ \text { TCPP } & 847 \pm 416 & 1307 \pm 338 & \text { n.a. } & 3040 \pm 901 \\ \text { TDCP } & 849 \pm 614 & 387 \pm 270 & 707 \pm 48 & 1237 \pm 884 \\ \text { TiBP } & 6064 \pm 510 & 586 \pm 117 & 2603 \pm 431 & 7357 \pm 675 \\ \text { TPhP } & 172 \pm 171 & 648 \pm 190 & 1611 \pm 264 & 3424 \pm 792 \\ \text { TnBP } & 2064 \pm 572 & 1771 \pm 254 & 599 \pm 104 & 5446 \pm 1091 \\ \text { CDPP } & \text { n.a. } & 1094 \pm 390 & 8026 \pm 1236 & 1693 \pm 494 \\ \text { TBEP } & 206 \pm 149 & 5919 \pm 1809 & 2314 \pm 311 & 14150 \pm 3193 \\ \text { TCrP } & 1049 \pm 304 & 5180 \pm 1458 & 364 \pm 84 & 8543 \pm 2073 \\ \text { EHDPP } & 68 \pm 39 & 109 \pm 63 & 1067 \pm 352 & 541 \pm 187 \\ \text { TEHP } & \text { n.a. } & 19 \pm 19 & 18176 \pm 2290 & 1087 \pm 371 \\ \sum_{14} \text { OPEs } & 13019 \pm 2063 & 17017 \pm 3648 & 48212 \pm 8001\end{array}$

${ }^{a}$ Load was estimated using eq $S 1$ with the concentrations measured in Ponar grab samples. Standard error of the load was estimated from the standard error of the inventory. " "n.a." indicates the estimated total load $<1 \mathrm{~kg}$. ${ }^{c}$ Italic numbers indicate lower than $30 \%$ detection rate thus the data should be interpreted with caution.

(M009, M011, and M061) and near Sleeping Bear Dunes (M093a). Sampling sites near Chicago and Milwaukee (M010, M020, and M030) are in nondepositional zone of Lake Michigan; sediments collected from these sites were sandy with less organic carbon $(<2.5 \mathrm{mg} / \mathrm{g} \mathrm{dw})$. Pollutants entering the lake from these urban/industrial areas tend to transport with the water flow in the counterclockwise gyre of the southern basin, and deposit on the southeast side of the lake. In Lake Ontario, concentrations and inventories of $\Sigma_{14} \mathrm{OPEs}$ were in general higher in the eastern basin than in the central and west basins. However, inventory of $\Sigma_{14}$ OPEs greater than $200 \mathrm{ng}$ $\mathrm{cm}^{-2}$ was found near Toronto (ON03) and the Niagara River (ON06 and ON08), and along the south coast (ON12). Fish collected near ON06 have been found to have higher levels of some OPEs than other sites across Canada. ${ }^{15}$

TBEP, TCrP, and TPhP were the most abundant OPEs in sediments across the three lakes (Table S5 and Figure S2). TBEP and TCrP are mainly used as additives in plastic products, rubber, floor cleaning agents, wallpaper and other consumer goods, as well as in the production of cables and electrical appliances. ${ }^{3,35}$ TBEP is the major OPE congener in waters of the Great Lakes. ${ }^{12}$ These congeners have $K_{\mathrm{oc}}$ near or higher than $10^{4}$ (Table S1), thus greater association with sediments than most other OPEs measured in this work. Although concentrations of $\mathrm{TiBP}$ and $\mathrm{TnBP}$ were relatively low, their concentrations exceeded the method detection limits (MDL) in 97\% of samples. TiBP and TnBP are important components of hydraulic and lubricating oils, ${ }^{3}$ and thus could be released from equipment on ships. Detection of EHDPP and TEHP occurred mostly in Lake Ontario. Together, all the three chlorinated OPEs (TCEP, TCPP, and TDCP) accounted for $10.6 \%$ of $\Sigma_{14}$ OPEs, and TCPP was the most abundant among chlorinated OPEs. TCPP has been used in rigid and flexible polyurethane foams, and to replace the more toxic TCEP. ${ }^{3}$ It was reported as the most abundant chlorinated congener in the atmosphere ${ }^{10}$ and water ${ }^{12}$ in the Great Lakes region. The highly polar congeners TMP, TEP, and TPrP were detected in $<19 \%$ of the Ponar grab samples, and together accounting for less than $1.5 \%$ of $\Sigma_{14}$ OPEs in the sediment.

Associations between concentrations of OPEs for which detection frequencies were greater than $85 \%$ were investigated by use of Spearman rank correlations (nonparametric test). Correlations among the OPEs varied among lakes (Table S7). In Lake Superior, TiBP and TnBP were significantly correlated, and normalization to $\mathrm{OC}$ strengthened the correlation. These may suggest that $\mathrm{TiBP}$ and $\mathrm{TnBP}$ in the lake share similar sources. In Lake Michigan, TBEP and TCrP were significantly correlated. In Lake Ontario, TnBP, TPhP, TBEP, and TCrP were significantly correlated. However, in Lakes Michigan and Ontario, normalization to OC content did not strengthen the correlations between congeners, which suggests that the impact of local sources may outweigh the influence of sediment organic matter on the OPE concentrations in these two lakes.

With the measured concentrations, inventories of OPEs at each sampling sites were estimated using eq S1. The inventories of $\Sigma_{14} \mathrm{OPEs}$ estimated from using the concentrations from cores collected at sites M009, M024, and M047 were 178, 38, and $44 \mathrm{ng} \mathrm{cm}^{-2}$, which were comparable with the estimates of 127,38 , and 13 obtained by the use of concentrations in Ponar grabs collected at the same sites (Table S4). With the use of eq S2, the total accumulation of $\Sigma_{14}$ OPEs in the sediments of the three lakes was estimated to be in the range of 40-60 tonnes (Table 1).

\section{DISCUSSION}

Spatial Distribution and Urban Impact. Chemical pollutants, which are released predominantly from anthropogenic sources, are likely to have higher concentrations at locations near urban and industrialized areas. To assess the urban impact on the spatial distribution of pollutants in the Great Lakes region, we previously developed urban distance factor (UDF) based on the population $(P)$ and distance between sampling site and cities $(D)$ in the region. ${ }^{32}$ In this work, the UDF database was expanded to include more communities on lake shores and metropolitan areas in the States and Province in the Great Lakes region, with updated population data of the 2010 and 2011 censuses in the U.S. and Canada, respectively. Seven different forms of UDF were calculated for each sampling location (SI Text). UDF2, which is defined as $P$ divided by square root of $D$, was found to correlate strongly with the natural logarithms of OC based concentrations $\left(r=0.35, p\right.$-value $\left.=9 \times 10^{-4}\right)$ or inventories $(r=0.56$, 
$p$-value $\left.=2 \times 10^{-8}\right)$ for $\Sigma_{14}$ OPEs, as well as individual OPE congeners with detection frequency $>60 \%$ in Ponar grab samples $\left(r>0.35\right.$ and $p<6 \times 10^{-4}$, excluding TCPP and TiBP for which $r>0.24$ and $p<0.03$ ). The UDF2 values are included in Table S2 for all the sampling locations.

In addition to potential source locations, the concentrations of OPEs exhibited increases with increasing sediment OC content. Studies on sorption mechanisms of OPEs on soil and sediment particles are currently scarce. ${ }^{36,37}$ While organic matter of the sediments accommodates nonpolar organics predominantly by hydrophobic interaction, stronger specific interactions involving electron donor/acceptor or hydrogen bond could occur between numerous polar functional groups of the natural organic matter and the polar moieties of sorbates such as OPEs. With UDF2 and sediment OC content as independent variables, multiple linear regression models were developed and are presented in Figure 3 and Table S8.

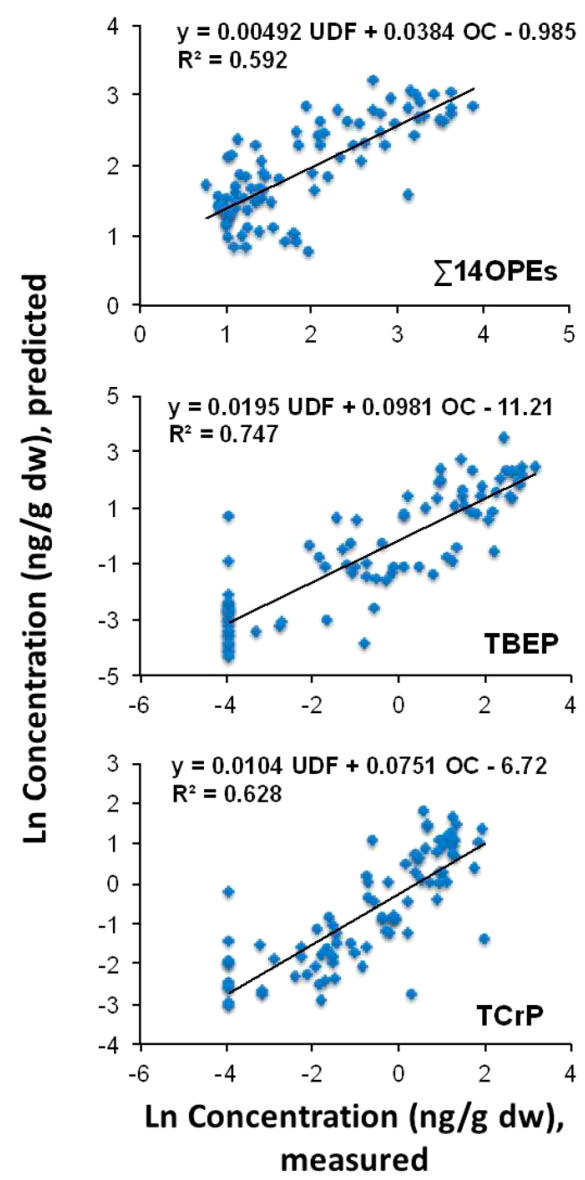

Figure 3. Comparison of predicted concentrations with measured concentrations of OPEs in Ponar grab sediments using the multivariable linear regression models $(N=88)$. The regression statistics are summarized in Table S8.

Sediment OC and impact of human activities are the main controlling factors influencing the distribution of OPEs in the sediment across the three lakes, together accounting for approximately $59 \%$ of the variance in concentration for $\Sigma_{14}$ OPEs.

There is evidence that OPEs undergo long-range atmospheric transport. ${ }^{10,38}$ The OPEs targeted in this work vary widely in their volatility, with vapor pressure ranging from $10^{-5}$ to $>100 \mathrm{~Pa}$ (Table S1). We found that the relative abundance of OPEs differs largely among the three lakes (Figure S2). In Lake Superior, the congeners with the greatest concentrations were relatively volatile TiBP and TnBP. In comparison, heavier congeners TBEP and TCrP had greater detection rates and concentrations in Lakes Michigan and Ontario. The mean ratio $(\mathrm{TiBP}+\mathrm{TnBP}) /(\mathrm{TBEP}+\mathrm{TCrP})$ in Lake Superior was 10.7, which is much greater than those in Lakes Michigan (1.9) and Ontario (0.46). With higher vapor pressures, TiBP and TnBP are more likely to enter air and reach remote locations via atmospheric transport. In contrast, the heavier TBEP and TCrP have greater $K_{\mathrm{oc}}$ thus are more likely to bind to sediments after local inputs.

Temporal Trends and Downward Mobility. OPEs have already been used for $>150$ years; ${ }^{3}$ however, information for production volume during the earlier years is not available. As shown in Figure 2, in deeper sediments dated before year 1900, concentrations of $\Sigma_{14}$ OPEs were low and relatively constant but still greater than the MDL. After 1900, concentrations and fluxes of $\Sigma_{14}$ OPEs began to increase and peaked in the 1970s to 1980s. A decrease was observed in sediments deposited in the 1990s; however, a rebound after 2000 was observed at all three sites although the number of data points is limited. At sites M047 and M024, the highest concentrations and fluxes of $\Sigma_{14}$ OPEs were in the uppermost segments of cores. At site M009, $\Sigma_{14}$ OPEs in surficial segment dated 2009 was $28 \mathrm{ng} \mathrm{g}^{-1}$ $\mathrm{dw}$, which is almost double $16 \mathrm{ng} \mathrm{g}^{-1} \mathrm{dw}$ observed in sediments deposited during the late 1990s, although still below the historical peak of $41 \mathrm{ng} \mathrm{g}^{-1} \mathrm{dw}$ in core segment deposited during the 1960s (Figure 2). Net depositional fluxes of OPEs at these sites were estimated using eq S3. The recent depositional fluxes were $0.83,0.19$, and $0.25 \mathrm{ng} \mathrm{m}^{-2} \mathrm{yr}^{-1}$ for $\Sigma_{14}$ OPEs at sites M009, M024, and M047, respectively. The observations are clear evidence of the re-emergence of OPEs as environment pollutants. The recent increasing trend is consistent with observations of OPEs in other environmental matrices, ${ }^{7,39}$ and can be attributed to large scale replacement of PBDEs with OPE flame retardants in consumer goods. ${ }^{4,40,41}$ The observed increases in the environment may also reflect the tripled worldwide production volume of OPEs-from approximately 100000 tonnes per year in 1992 to 341000 tonnes per year in $2007 .^{42}$

Different time trends were observed among targeted OPEs. The above-mentioned increases in recent years appear to be dominated by the rapid increase of chlorinated congeners (Figure 2, lower panels), especially TCPP. Exponential increases were observed for TCPP at all three coring sites since the 1950s, with apparent doubling time $t_{2}$ around 20 years (Figure 4). It has been reported that the consumption of TCPP has continued to increase since the mid-1960s. ${ }^{43}$ After the phase-out of the more toxic TCEP and with increasing use of polyurethane foam, production of TCPP (a replacement of TCEP) has increased markedly from the 1980 s. $^{43}$ In 2000 , worldwide production of TCPP was $36,000 \mathrm{t}$; in recent years, TCPP represents $\sim 80 \%$ of the chlorinated OPEs produced in Europe. ${ }^{44}$ TCPP was found to be the dominant (at $180 \mathrm{ng} / \mathrm{g}$ ) among eight OPEs in the sediment of Liverpool Bay and the Rivers Mersey and Tees in the U.K. ${ }^{45}$ It was detected in air, water, and bird eggs from the Great Lakes region. ${ }^{10-14,16}$ These observations highlight the need to establish benchmarks for TCPP in various environmental media to prevent adverse biological effects. In contrast to TCPP, all alkyl and aryl OPEs with the exception of TBEP decreased expoentially at site M009 after 1960, with apparent half-lives $\left(t_{0.5}\right)$ ranging from 15 

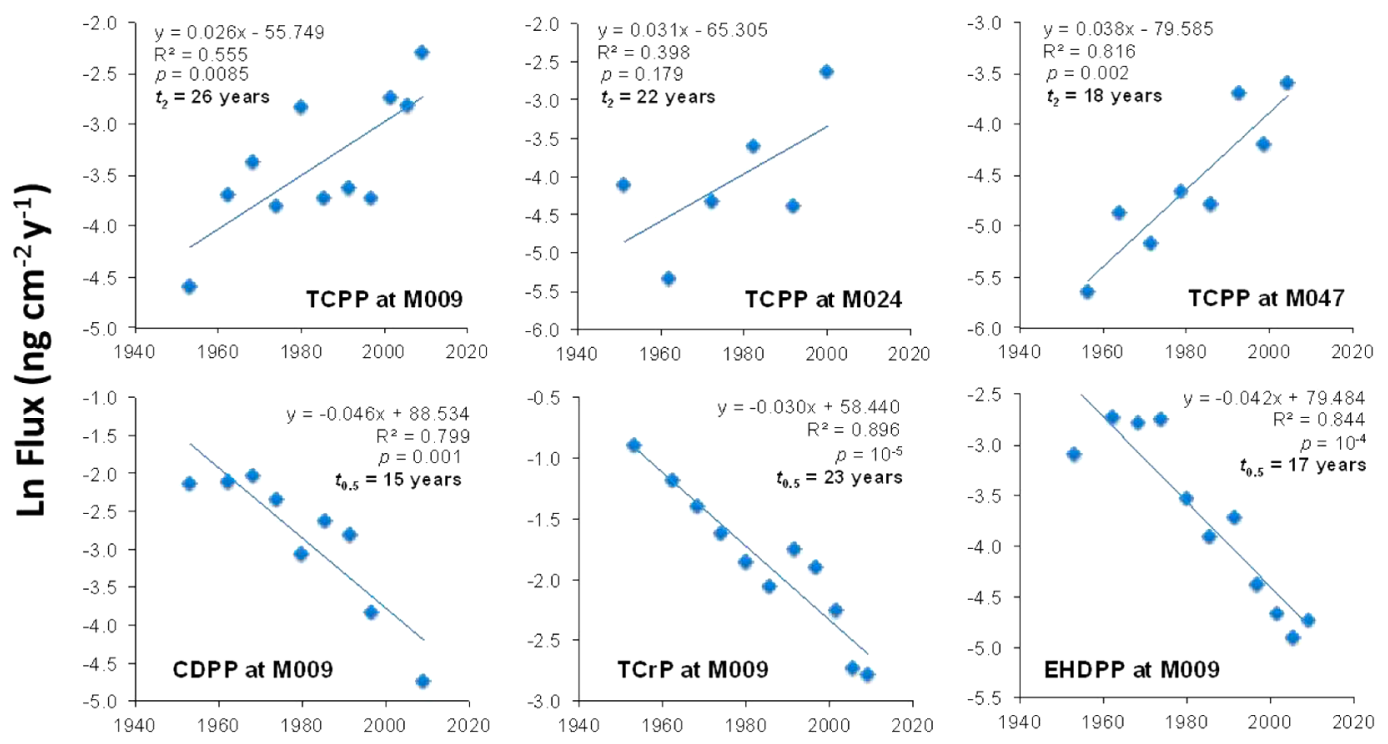

Deposition Year

Figure 4. First-order kinetics plots of net depositional flux of selected OPEs to sediment of Lake Michigan. Only core segments dated after 1950 are included, and the apparent doubling time $t_{2}$ and half-life $t_{0.5}$ are calculated as $\ln 2$ divided by the slopes of the regressions.

to 40 years (Figure 4). The production of TCrP was predicted to decline $\sim 5 \%$ each year during the period of $1978-1982 .{ }^{46}$ TBEP displayed no trend over the core depth. Both increases and decreases in the depositional fluxes were observed at M024 and M047 depending on individual OPEs, but most trends were statistically insignificant $(p>0.05)$.

For compounds that are relatively water-soluble, therefore mobile in aqueous phase, the chronological profile recorded in dated sediment cores may not be in good agreement with the actual deposition history. For example, extensive downward transport of herbicide atrazine $\left(\log K_{\mathrm{oc}}=2.35\right)$ as well as some perfluorinated compounds in sediment cores of Lake Michigan was reported. ${ }^{23,24}$ Assuming equilibrium conditions, the distribution between particle and pore water of sediment depends on hydrophobicity of the chemical $\left(\log K_{\mathrm{oc}}\right)$, the solidto-water mass ratio $\left(r_{\mathrm{sW}}\right)$, and the organic content of the particles $\left(f_{\mathrm{oc}}\right)$, but is independent of chemical concentration. Thus, the fraction of the compound in pore water of the sediment can be estimated using the equation below. ${ }^{47}$ Figure $5 \mathrm{~A}$ illustrates the results of applying this equation to the sediment of this work.

$$
f_{\mathrm{iw}}=\frac{1}{1+r_{\mathrm{sw}} \cdot K_{\mathrm{oc}} \cdot f_{\mathrm{oc}}}
$$

The targeted OPEs vary widely in their affinity to organic matter, with $\log K_{\mathrm{oc}}$ ranging from 1.10 to 6.87 (Table S1). It is clear from Figure $5 \mathrm{~A}$, while OPEs with $\log K_{\mathrm{oc}}>\sim 5$ are almost completely associated with sediment particles, a significant portion of OPEs with $\log K_{\mathrm{oc}}<\sim 3$ can be present in pore water. This may have facilitated postdepositional transport to deeper sediment due to downward diffusion over time. We observed that, in all three cores, the summed fraction of less hydrophobic congeners $\left(\log K_{\mathrm{oc}}<3.5\right)$ exhibits a rapid rise to near unity in deeper sediment (Figure 5B). Higher downward mobility of the more polar congeners relative to those more hydrophobic is likely to cause fractionation of a chemical mixture over the depth of sediments in a sufficiently long time period. The occurrence of natural fractionation of the OPEs in
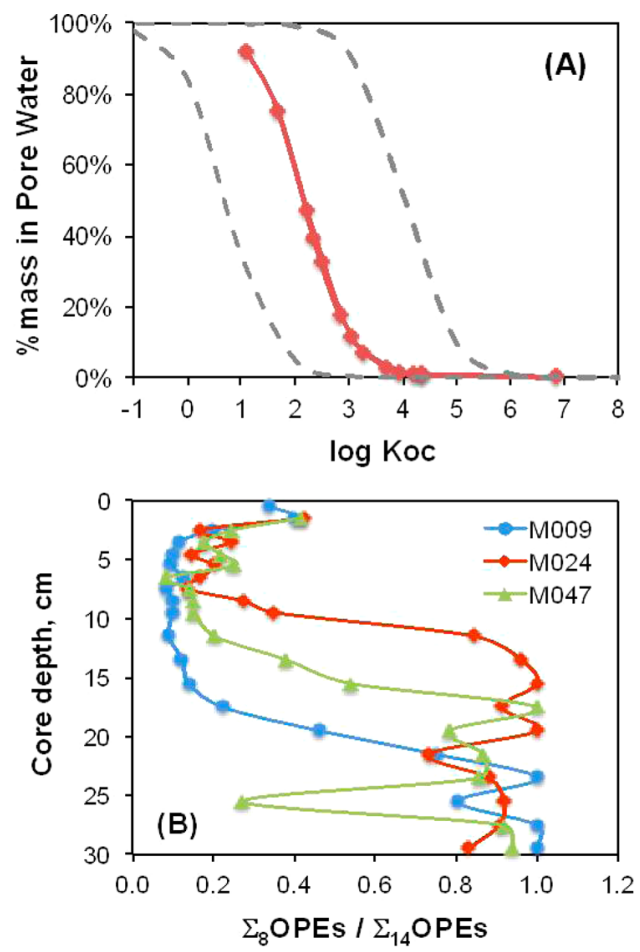

Figure 5. (A) Mass percent of OPEs that are present in pore water, calculated using eq 1 . The dashed line on the right is drawn using the lowest OC content $(0.55 \mathrm{mg} / \mathrm{g} \mathrm{dw})$ and the lowest solid-water mass ratio $(0.17 \mathrm{~kg} / \mathrm{L})$, while the dashed line on the left using the highest OC content $(50.6 \mathrm{mg} / \mathrm{g} \mathrm{dw})$ and the highest solid-water mass ratio $(3.76 \mathrm{~kg} / \mathrm{L})$, measured in the Ponar grab samples of this work. The red dots are the median values of individual OPEs in all Ponar grab samples. (B) Variation with sediment depth of summed fraction of the 8 relatively polar OPEs $\left(\log K_{\mathrm{oc}}<3.5\right)$ in three cores from Lake Michigan.

lake sediments over time is yet to be confirmed by future studies. Congener-specific information on the production and use history, especially that before 1900, is highly desired. 
Transformation after burial is another process that may affect the apparent time trend observed in sediment cores. Nonchlorinated alkyl and aryl OPEs, such as TiBP, TnBP, TCrP, $\mathrm{TPhP}$, and TBEP, tend to be more readily biodegradable than chlorinated OPEs such as TCPP, TCEP, and TDCP. ${ }^{7,42}$ However, the occurrence of degradation of OPEs cannot be confirmed based on the chronological profiles recorded in the three sediment cores of this work.

Load Estimation and Phase Distribution between Water and Sediment. Concentration data are available for 11 OPEs dissolved in bulk water samples collected in spring 2012 from Lake Michigan, at a central location (latitude 44.2, longitude -87.3) and a southern location (latitude 41.9, longitude -87.6). ${ }^{12}$ By multiplying the volume of water in Lake Michigan $\left(4,920 \mathrm{~km}^{3}\right)$ with the reported $\Sigma$ OPEs concentration $(9.3 \mathrm{ng} / \mathrm{L}){ }^{12}$ the total load of OPEs dissolved in the lake water is roughly 46 tonnes. Compared with the total load of 17 tonnes in the sediment (Table 1), it appears that about $27 \%$ of the OPEs in Lake Michigan resides in the sediment. This percentage is about $20 \%$ if the calculation is based on the same set of seven congeners (TCEP, TCPP, TDCP, TPhP, TnBP, TBEP, and TEHP) reported in water ${ }^{12}$ and sediment. The sum of 63 tonnes does not include the amounts in suspended or settling particulates and living biota, for which data are not available.

TCPP, TnBP, and TBEP had $>50 \%$ detection frequency in this work in the Ponar grab sediment samples collected in lower (latitude <45) Lake Michigan $(N=9)$. With their concentrations in the bulk water, ${ }^{12}$ bulk phase distribution ratio, which is defined here as the measured concentration in the sediment organic carbon ( $\mathrm{ng} \mathrm{kg}^{-1} \mathrm{OC}$ ) to that in water (ng $\mathrm{L}^{-1}$ ), was calculated for the three congeners. Different pairs of sediment and water sampling sites were tested. For example, the ratio was calculated by the use of only one sediment site that is the nearest to each water sampling site, a number of sediment sites in proximity to each of the water sampling sites, areas divided by latitude, or lake-wide average from all sediment sites to the average at the two water sampling sites. The calculated distribution ratio ranged from $10^{4.0}$ to $10^{5.2} \mathrm{~L} / \mathrm{kg}$ for TCPP, which is 2 to 3 orders of magnitude higher than its $K_{\mathrm{oc}}$ value of $10^{2.2} \mathrm{~L} / \mathrm{kg}$ (Table S1). Similarly, the distribution ratio of TnBP ranged from $10^{4.7}$ to $10^{5.3} \mathrm{~L} / \mathrm{kg}$, much higher than its $K_{\mathrm{oc}}$ of $10^{3.28} \mathrm{~L} / \mathrm{kg}$. However, the distribution ratio of TBEP, ranging from $10^{3.8}$ to $10^{4.8} \mathrm{~L} / \mathrm{kg}$, matched well with its $K_{\mathrm{oc}}$ of $10^{4.38} \mathrm{~L} / \mathrm{kg}$. Such differences were found to be much greater in the southern basin than the central area of the lake. The gaps between the distribution ratio and $K_{\mathrm{oc}}$ were also reported to be greater for PCBs with lower $\log K_{\mathrm{ow}}$ values; alteration of the natural organic matter composition and sorption kinetics are among plausible explanations. ${ }^{48}$ The results of this work for OPEs suggest that the difference between the distribution ratio and $K_{\mathrm{oc}}$ could also be time- and location-related, as the gap tends to be more pronounced for emerging and re-emerging pollutants such as TCPP, and at near-source locations. The significance of these findings with regard to bioavailability and sediment risk assessment is yet to be fully realized.

This work provides solid evidence that sediment of the Great Lakes has been contaminated with quantifiable levels of OPE flame retardants and plasticizers, and that the deposition of some OPEs to sediment appears to be accelerating. Due to their continued uses in North America, the input of OPEs to sediment of the Great Lakes may continue for years to come. The possibility that the contaminated sediment act as a secondary source releasing OPEs to the overlaying water warrants future studies.

\section{ASSOCIATED CONTENT}

\section{Supporting Information}

The Supporting Information is available free of charge on the ACS Publications website at DOI: 10.1021/acs.est.6b05484.

Detailed methods, structures, and physical and chemical properties of organophosphate esters (Table S1), sampling site information (Table S2), analytical parameters and quality control using LC-MS/MS (Table S3), concentrations and inventories of $\Sigma_{14}$ OPEs in Ponar grab sediments (Table S4), concentration and detection rate of individual OPEs in the Ponar grab sediments of Lakes Ontario, Michigan, and Superior (Table S5), concentration of individual OPEs and $\Sigma_{14}$ OPEs and the flux of $\Sigma_{14}$ OPEs in sediment cores from Lake Michigan (Table S6), Spearman's correlation coefficient among OPEs (Table S7), multiple linear regressions statistics by SPSS (Table S8), LC-MS/MS extracted ion chromatograms of a sediment extract and OPE standard mixture (Figure S1), and relative abundance of individual OPEs in Ponar grab sediments (Figure S2) (PDF)

\section{AUTHOR INFORMATION}

\section{Corresponding Authors}

*Phone: +86 010 62849124; fax: +86010 62849124; e-mail: ywwang@rcees.ac.cn (Y.W.).

*Phone: 1-312-996-9597; fax: 1-312-413-9898; e-mail: anli@ uic.edu (A.L.).

ORCID ${ }^{\circ}$

Yawei Wang: 0000-0002-6115-4076

Margaret B. Corcoran: 0000-0002-9114-0230

Jingfu Liu: 0000-0001-7134-7026

\section{Present Addresses}

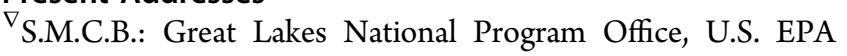
Region V, Chicago, Illinois, United States.

${ }^{\mathbb{I l}}$ M.B.C.: CSRA LLC, Schaumburg, Illinois, United States.

ON.C.S.: Department of Geological Sciences, University of Delaware, Newark, Delaware, United States.

\section{Notes}

The authors declare no competing financial interest.

\section{ACKNOWLEDGMENTS}

This research was part of the Great Lakes Sediment Surveillance Program (GLSSP). This work was supported by a Cooperative Agreement from the U.S. EPA Great Lakes Restoration Initiative with Assistance No. GL-00E00538 (EPA Program Officer Todd Nettesheim), the National Natural Science Foundation of China (21625702, 21407157), the National Basic Research Program of China (2015CB453102), and the Strategic Priority Research Program of the Chinese Academy of Science (XDB14010400). J.G. and S.H. were also supported by the Predoctoral Fellowship provided by the Institute for Environmental Science and Policy at the University of Illinois at Chicago (UIC). Prof. Giesy was supported by the Canada Research Chair program, the 2012 "High Level Foreign Experts" (\#GDT20143200016) program, funded by the State Administration of Foreign Experts Affairs, the P.R. China to Nanjing University and the Einstein Professor Program of the Chinese Academy of Sciences and a Distinguished Visiting 
Professorship in the School of Biological Sciences of the University of Hong Kong. We thank the crews of $R / V$ Lake Guardian for assistance during sediment sampling.

\section{REFERENCES}

(1) USEPA. The manufacture and use of selected aryl and alkyl aryl phosphate esters (Task I), EPA 560/6-76-008, 1976.

(2) USEPA. Environmental profiles of chemical flame-retardant alternatives for low-density polyurethane foam, EPA 742-R-05-002B, 2005.

(3) van der Veen, I.; de Boer, J. Phosphorus flame retardants: Properties, production, environmental occurrence, toxicity and analysis. Chemosphere 2012, 88 (10), 1119-1153.

(4) Tullo, A. Great Lakes to phase out flame retardants. Chem. Eng. News 2003, 81 (45), 13.

(5) Stapleton, H. M.; Sharma, S.; Getzinger, G.; Ferguson, P. L.; Gabriel, M.; Webster, T. F.; Blum, A. Novel and high volume use flame retardants in US couches reflective of the 2005 pentaBDE phase out. Environ. Sci. Technol. 2012, 46 (24), 13432-13439.

(6) Venier, M.; Salamova, A.; Hites, R. A. Halogenated flame retardants in the Great Lakes environment. Acc. Chem. Res. 2015, 48 (7), 1853-1861.

(7) Reemtsma, T.; Quintana, J. B.; Rodil, R.; Garcia-Lopez, M.; Rodriguez, I. Organophosphorus flame retardants and plasticizers in water and air I. Occurrence and fate. TrAC, Trends Anal. Chem. 2008, 27 (9), 727-737.

(8) Ding, J. J.; Xu, Z. M.; Huang, W.; Feng, L. M.; Yang, F. X. Organophosphate ester flame retardants and plasticizers in human placenta in Eastern China. Sci. Total Environ. 2016, 554, 211-217.

(9) Phosphate Ester Flame Retardant Consortium. http://www. pefrcnet.org/members.asp (accessed February 1, 2016).

(10) Salamova, A.; Ma, Y.; Venier, M.; Hites, R. A. High levels of organophosphate flame retardants in the Great Lakes atmosphere. Environ. Environ. Sci. Technol. Lett. 2014, 1 (1), 8-14.

(11) Shoeib, M.; Ahrens, L.; Jantunen, L.; Harner, T. Concentrations in air of organobromine, organochlorine and organophosphate flame retardants in Toronto, Canada. Atmos. Environ. 2014, 99, 140-147.

(12) Venier, M.; Dove, A.; Romanak, K.; Backus, S.; Hites, R. Flame retardants and legacy chemicals in Great Lakes' water. Environ. Sci. Technol. 2014, 48 (16), 9563-9572.

(13) Chen, D.; Letcher, R. J.; Chu, S. G. Determination of nonhalogenated, chlorinated and brominated organophosphate flame retardants in herring gull eggs based on liquid chromatographytandem quadrupole mass spectrometry. J. Chromatogr. A 2012, 1220, $169-174$.

(14) Greaves, A. K.; Letcher, R. J. Comparative body compartment composition and in ovo transfer of organophosphate flame retardants in north American Great Lakes herring gulls. Environ. Sci. Technol. 2014, 48 (14), 7942-7950.

(15) McGoldrick, D. J.; Letcher, R. J.; Barresi, E.; Keir, M. J.; Small, J.; Clark, M. G.; Sverko, E.; Backus, S. M. Organophosphate flame retardants and organosiloxanes in predatory freshwater fish from locations across Canada. Environ. Pollut. 2014, 193, 254-261.

(16) Greaves, A. K.; Letcher, R. J.; Chen, D.; McGoldrick, D. J.; Gauthier, L. T.; Backus, S. M. Retrospective analysis of organophosphate flame retardants in herring gull eggs and relation to the aquatic food web in the Laurentian Great Lakes of North America. Environ. Res. 2016, 150, 255-263.

(17) Cao, S. X.; Zeng, X. Y.; Song, H.; Li, H. R.; Yu, Z. Q.; Sheng, G. Y.; $\mathrm{Fu}, \mathrm{J}$. M. Levels and distributions of organophosphate flame retardants and plasticizers in sediment from Taihu Lake, China. Environ. Toxicol. Chem. 2012, 31 (7), 1478-1484.

(18) Martinez-Carballo, E.; Gonzalez-Barreiro, C.; Sitka, A.; Scharf, S.; Gans, O. Determination of selected organophosphate esters in the aquatic environment of Austria. Sci. Total Environ. 2007, 388 (1-3), 290-299.

(19) Cristale, J.; Vazquez, A. G.; Barata, C.; Lacorte, S. Priority and emerging flame retardants in rivers: Occurrence in water and sediment, Daphnia magna toxicity and risk assessment. Environ. Int. 2013, 59, 232-243.

(20) Peverly, A. A.; O'Sullivan, C.; Liu, L. Y.; Venier, M.; Martinez, A.; Hornbuckle, K. C.; Hites, R. A. Chicago's Sanitary and Ship Canal sediment: Polycyclic aromatic hydrocarbons, polychlorinated biphenyls, brominated flame retardants, and organophosphate esters. Chemosphere 2015, 134, 380-386.

(21) Persistent, Bioaccumulative, and Toxic Profiles Estimated for Organic Chemicals On-Line, 2006. http://www.pbtprofiler.net/ (accessed September 5, 2016).

(22) Bonina, S. Carbon loading to Lake Michigan sediments. Ph. D. Dissertation, University of Illinois at Chicago, Chicago, IL, 2016.

(23) Codling, G.; Vogt, A.; Jones, P. D.; Wang, T. Y.; Wang, P.; Lu, Y. L.; Corcoran, M.; Bonina, S.; Li, A.; Sturchio, N. C.; Rockne, K. J.; Ji, K.; Khim, J. S.; Naile, J. E.; Giesy, J. P. Historical trends of inorganic and organic fluorine in sediments of Lake Michigan. Chemosphere 2014, 114, 203-209.

(24) Guo, J.; Li, Z.; Ranasinghe, P.; Bonina, S.; Hosseini, S.; Corcoran, M. B.; Smalley, C.; Kaliappan, R.; Wu, Y.; Chen, D.; Sandy, A. L.; Wang, Y.; Rockne, K. J.; Sturchio, N. C.; Giesy, J. P.; Li, A. Occurrence of atrazine and related compounds in sediments of upper Great Lakes. Environ. Sci. Technol. 2016, 50 (14), 7335-7343.

(25) Song, W. L.; Ford, J. C.; Li, A.; Mills, W. J.; Buckley, D. R.; Rockne, K. J. Polybrominated diphenyl ethers in the sediments of the great lakes. 1. Lake superior. Environ. Sci. Technol. 2004, 38 (12), 3286-3293.

(26) Song, W. L.; Li, A.; Ford, J. C.; Sturchio, N. C.; Rockne, K. J.; Buckley, D. R.; Mills, W. J. Polybrominated diphenyl ethers in the sediments of the great lakes. 2. Lakes Michigan and Huron. Environ. Sci. Technol. 2005, 39 (10), 3474-3479.

(27) Song, W. L.; Ford, J. C.; Li, A.; Sturchio, N. C.; Rockne, K. J.; Buckley, D. R.; Mills, W. J. Polybrominated diphenyl ethers in the sediments of the Great Lakes. 3. Lakes Ontario and Erie. Environ. Sci. Technol. 2005, 39 (15), 5600-5605.

(28) Wang, W.; Delgado-Moreno, L.; Ye, Q. F.; Gan, J. Improved measurements of partition coefficients for polybrominated diphenyl ethers. Environ. Sci. Technol. 2011, 45 (4), 1521-1527.

(29) Chen, M. Y.; Yu, M.; Luo, X. J.; Chen, S. J.; Mai, B. X. The factors controlling the partitioning of polybrominated diphenyl ethers and polychlorinated biphenyls in the water-column of the Pearl River Estuary in South China. Mar. Pollut. Bull. 2011, 62 (1), 29-35.

(30) Kawagoshi, Y.; Fukunaga, I.; Itoh, H. Distribution of organophosphoric acid triesters between water and sediment at a sea-based solid waste disposal site. J. Mater. Cycles Waste Manage 1999, 1 (1), 53-61.

(31) Stachel, B.; Jantzen, E.; Knoth, W.; Kruger, F.; Lepom, P.; Oetken, M.; Reincke, H.; Sawal, G.; Schwartz, R.; Uhlig, S. The Elbe flood in August 2002 - Organic contaminants in sediment samples taken after the flood event. J. Environ. Sci. Health, Part A: Toxic/ Hazard. Subst. Environ. Eng. 2005, 40 (2), 265-287.

(32) Li, A.; Rockne, K. J.; Sturchio, N.; Song, W. L.; Ford, J. C.; Buckley, D. R.; Mills, W. J. Polybrominated diphenyl ethers in the sediments of the Great Lakes. 4. Influencing factors, trends, and implications. Environ. Sci. Technol. 2006, 40 (24), 7528-7534.

(33) Yang, R. Q.; Wei, H.; Guo, J. H.; McLeod, C.; Li, A.; Sturchio, N. C. Historically and currently used dechloranes in the sediments of the Great Lakes. Environ. Sci. Technol. 2011, 45 (12), 5156-5163.

(34) Yang, R. Q.; Wei, H.; Guo, J. H.; Li, A. Emerging brominated flame retardants in the sediment of the Great Lakes. Environ. Sci. Technol. 2012, 46 (6), 3119-3126.

(35) Flame Retardants: Tris (2-butoxyethyl) phosphate, tris(2ethylhexyl) phosphate and tetrakis (hydroxymethyl) phosphonium salts, 2000; pp 218.

(36) Zheng, C. L.; Feng, S. S.; Wang, Q. R.; Liu, P. P.; Shen, Z. X.; Liu, H. X.; Yang, L. Application of SPME-GC/MS to study the sorption of organophosphate esters on peat soil. Water, Air, Soil Pollut. 2016, 227 (7), 236.

(37) Pang, L.; Liu, J. F.; Yin, Y. G.; Shen, M. H. Evaluating the sorption of organophosphate esters to different sourced humic acids 
and its effects on the toxicity to Daphnia Magna. Environ. Toxicol. Chem. 2013, 32 (12), 2755-2761.

(38) Sühring, R.; Diamond, M. L.; Scheringer, M.; Wong, F.; Pucko, M.; Stern, G.; Burt, A.; Hung, H.; Fellin, P.; Li, H.; Jantunen, L. M. Organophosphate esters in canadian arctic air: Occurrence, levels and trends. Environ. Sci. Technol. 2016, 50 (14), 7409-7415.

(39) Stapleton, H. M.; Klosterhaus, S.; Eagle, S.; Fuh, J.; Meeker, J. D.; Blum, A.; Webster, T. F. Detection of organophosphate flame retardants in furniture foam and US house dust. Environ. Sci. Technol. 2009, 43 (19), 7490-7495.

(40) EU, Directive 2003/11/EC of the European Parliament and of the Council. In Official Journal of the European Union: 2001; Vol. Directive 76/769/EEC, pp 45-46.

(41) USEPA. DecaBDE phase-out initiative, 2009.

(42) Greaves, A. K.; Letcher, R. J. A review of organophosphate esters in the environment from biological effects to distribution and fate. Bull. Environ. Contam. Toxicol. 2017, 98 (1), 2-7.

(43) WHO. EHC 209: Flame Retardants: Tris-(Chloropropyl) Phosphate and Tris-(2-Chloroethyl)phosphate, Geneva, Switzerland, 1998.

(44) Leisewitz, A.; Kruse, H.; Schramm, E. Substituting Environmentally Relevant Flame Retardants: Assessment Fundamentals; Umweltbundesamt, Berlin, 2001.

(45) VU-IVM. Amsterdam, The Netherlands, 2007. Minutes of the Quasimeme Workshop on Brominated Flame Retardants (23-24 April), www.quasimeme.org.

(46) Muir, D. C. G. Phosphate esters. In The Handbook of Environmental Chemistry: Part C. Anthropogenic Compounds; Hutzinger, O., Eds.; Springer-Verlag: New York, 1984; Vol. 3, pp $41-66$.

(47) Schwarzenbach, R. P., Gschwend, P. M., Imboden, D. M. Environmental Organic Chemistry; John Wiley \& Sons: New York, 2005, Chapter 9.

(48) Gobas, F. A. P. C.; MacLean, L. G. Sediment-water distribution of organic contaminants in aquatic ecosystems: The role of organic carbon mineralization. Environ. Sci. Technol. 2003, 37 (4), 735-741. 